\title{
Genetic Variation Among Fusarium oxysporum Isolates Associated with Root Rot of Amaranthus hybridus in South Africa
}

\author{
Wei-Qun Chen and W. J. Swart, Department of Plant Pathology, Faculty of Agriculture, The University of the
} Free State, P.O. Box 339, Bloemfontein 9300, South Africa

\begin{abstract}
Chen, W. Q., and Swart, W. J. 2001. Genetic variation among Fusarium oxysporum isolates associated with root rot of Amaranthus hybridus in South Africa. Plant Dis. 85:1076-1080.

Thirty isolates of Fusarium oxysporum were recovered from six substrates: (i) tap roots of Amaranthus hybridus showing symptoms of root rot, (ii) side roots of A. hybridus showing symptoms of root rot, (iii) soil surrounding plants of A. hybridus, (iv) pigweed weevils (Hypolixus haerens) that feed on A. hybridus, (v) rhizosphere of maize plants growing adjacent to a field of amaranth, and (vi) rhizosphere of dry bean plants growing adjacent to a field of amaranth. The isolates were characterized by means of pathogenicity tests, isozyme analysis, and vegetative compatibility group (VCG) tests. In the pathogenicity tests, toothpick tips were infested with $F$. oxysporum and inserted into amaranth stems. All 30 isolates were pathogenic on A. hybridus, with significant differences in pathogenicity based on lesion length measured 4 weeks after inoculation. The isolates were grouped into nine VCGs by complementation tests using nitrate nonutilizing mutants. Self-incompatibility was not observed for any of the isolates. The most common VCG was VCG1, which comprised 20 of the 30 isolates tested. The second most common group was VCG3, which included three isolates, while the remaining seven VCGs each consisted of a single isolate. The results indicate that the population of the amaranth root rot pathogen examined in this study is relatively homogeneous. Results of the isozyme analysis supported the results of VCG tests. Three major groups were delineated within the 30 isolates of $F$. oxysporum following cluster analysis of electrophoretic phenotypic values for seven isozymes (EST, IDH, G6PDH, ACP, PEP1, PEP2, and PEP3) tested. No relationship was found between isozyme phenotype and the substrate from which the isolates were recovered.
\end{abstract}

Fusarium oxysporum Schlechtend. emend. W. C. Snyder \& H. N. Hans. is an important and cosmopolitan fungal species commonly found in a wide range of soils (13). The different formae speciales of $F$. oxysporum are responsible for wilt and root rot of more than 100 economicallyimportant plants (18). In South Africa, isolates of $F$. oxysporum have been associated with stem decay (1) and root rot (4) of Amaranthus hybridus L., a nutritious, rapidly growing vegetable produced on increasing acreage in semiarid regions of the country. The fungus was also shown to be the predominant fungal species vectored by the pigweed weevil Hypolixus haerens, the

Corresponding authors: W. Q. Chen and W. J. Swart

E-mail addresses: wqchen@uckac.edu and swartwj@sci.uovs.ac.za

Permanent address of W. Q. Chen: Department of Plant Protection, Northwest Sci-Tech University of Agriculture and Forestry, Yangling, Shaanxi, 712100 China.

This work was funded by the NRF (National Research Foundation) of South Africa as a postdoctoral bursary to W. Q. Chen.

Accepted for publication 12 June 2001.

Publication no. D-2001-0723-04R

(C) 2001 The American Phytopathological Society main insect pest of A. hybridus in South Africa $(15,19)$.

Genetic diversity within populations of $F$. oxysporum has been characterized extensively by means of vegetative compatibility group (VCG) tests (5,79,12,14,17,27). Detailed studies by Kistler et al. (18) showed that isolates belonging to the same VCG typically possess very similar or identical multilocus haplotypes and belong to the same clonal lineage. Isozyme analysis has also proved to be a useful tool for differentiating intraspecies variability among isolates of $F$. oxysporum recovered from diverse substrates $(3,11,23,25)$.

The primary objective of this study was to examine the genetic relatedness of 30 isolates of $F$. oxysporum obtained from an isolated field planted to amaranth for three successive growing seasons, from pigweed weevils, and from an adjacent field of maize and dry bean, using VCG tests, isozyme analysis, and pathogenicity tests. The secondary objective was to assess possible relationships among the three methods used for differentiating the isolates of $F$. oxysporum.

\section{MATERIALS AND METHODS}

Sample collection, culture isolation, and identification. Forty amaranth plants displaying symptoms of root rot were collected at random from a 0.25 -ha plot of 2- month-old plants of A. hybridus on an experimental farm near Bloemfontein, South Africa. The predominant soil type in the area was a medium loam (10 to $20 \%$ clay) with a mean $\mathrm{pH}$ of 7.4. The site had been planted to $A$. hybridus for the preceding 3 years and commercial fertilizer had been applied periodically to meet a nitrogen requirement of $160 \mathrm{~kg} / \mathrm{ha}$. Isolates of $F$. oxysporum were recovered from (i) the tap roots of amaranth plants showing typical root rot symptoms, (ii) the lateral roots of amaranth plants showing typical root rot symptoms, (iii) debris from the rhizosphere of diseased amaranth plants, (iv) pigweed weevils captuerd in the amaranth plot, (v) debris from the rhizosphere of dry bean plants, and (vi) debris from the rhizosphere of maize plants growing in two fields adjacent to the amaranth plot. Each field had been planted to maize and dry beans, respectively, for the previous 4 years with the same rate of fertilizer application as for the A. hybridus plot.

Foliage and petioles of symptomatic amaranth plants were cut off at a height of $50 \mathrm{~mm}$ or more above the root crown with a sterilized clipper and discarded. Each denuded plant stem was then placed in a separate plastic bag. The tap roots and side roots associated with collected plants were unearthed and shaken to remove adhering soil before being placed in separate plastic bags. Five soil samples (100 g each) were collected from each of five plants per host (amaranth, maize, and dry bean; i.e., a total of 25 soil samples per host plant). The soil samples were collected directly from the rhizosphere of the amaranth plants and randomly from the rhizosphere of maize plants and dry bean plants. Eighty adult pigweed weevils were collected over a period of 3 months during the summer of 1999. Upon capture, individual weevils were placed in 1.5-ml Eppendorf tubes to minimize possible cross-contamination of insects by fungal spores carried on their bodies. Weevils were killed in the lab by exposure to $-75^{\circ} \mathrm{C}$ for $2 \mathrm{~h}$. Each weevil was then plated aseptically onto $2 \%$ maltextract agar (MEA).

Tap root and side root samples from each of the 40 amaranth plants were trimmed, washed in running tap water to remove all soil, blotted dry, and cut into 10 -mm segments. Root segments were soaked in $0.5 \% \mathrm{NaOCl}$ for $5 \mathrm{~min}$, rinsed with sterile distilled water, dipped in $95 \%$ ethanol, and flamed briefly over a bunsen 
burner to allow for evaporation of the ethanol. Each segment was cleaved longitudinally with a sterilized scalpel. Three tap root samples and three side root samples were removed from each of the 40 amaranth plants, yielding a total of 120 of both tap and side root samples. Isolations from symptomatic roots were made onto potatodextrose agar (PDA) amended with streptomycin sulfate $(0.33 \mathrm{~g} / \mathrm{liter}$ of water $)$. Each longitudinal section was placed on a separate petri dish containing PDA. No isolations were made from asymptomatic roots.

Soil isolations were conducted from three replicate subsamples taken from a pooled, homogenized mixture of each of the five soil samples from each host. The soil was air dried at room temperature for $20 \mathrm{~min}$ and then passed through a $200-\mu \mathrm{m}$ sieve. Three subsamples of $8 \mathrm{mg}$ of soil from each sample were spread over Van Wyk's rose bengal-glycerine-urea selective medium for isolation of Fusarium spp. (28). Three plates were prepared for each replicate and incubated under daily schedules of $16 \mathrm{~h}$ fluorescent light and $8 \mathrm{~h}$ dark at room temperature for 6 days.

Fusarium colonies were observed microscopically. Those colonies identified as $F$. oxysporum were transferred to carnation-leaf agar (CLA) and PDA (22). Single spore isolations were made from each colony, and isolates were identified morphologically to species based on characteristics of the macroconidia, phialides, microconidia, chlamydospores, and colony growth traits (22).

Pathogenicity tests. Ten seeds of a single commercially planted cultivar (cv. 15/SA) of A. hybridus were planted in each of $304-\mathrm{cm}$-diameter plastic pots $(500 \mathrm{ml})$ containing a soil mixture (vol/vol) of $50 \%$ sand-loam (10 to $15 \%$ clay) and $50 \%$ peat. Soils were steam sterilized twice for $1 \mathrm{~h}$ at $80^{\circ} \mathrm{C}$ before planting seeds $10 \mathrm{~mm}$ deep. Plants were left to grow for 2 weeks before being transferred to larger plastic pots (1 liter) also containing steam-sterilized soil. Plants grew for a further 4 weeks before they were inoculated with the tips of wooden toothpicks colonized by each of the 30 isolates of $F$. oxysporum. Wooden toothpick tips (6 to $7 \mathrm{~mm}$ long) were autoclaved for $20 \mathrm{~min}$ in distilled water, removed from the water, blotted dry, autoclaved a second time in water to remove substances that might inhibit fungal growth, then autoclaved for a third time in potato-dextrose broth (PDB). The toothpick tips were cooled in a sterile petri dish and transferred individually to the margins of colonies of $F$. oxysporum on PDA. After incubation under fluorescent light at room temperature for $48 \mathrm{~h}$, the colonized toothpick tips were removed and used as an inoculum source. A single toothpick tip was inserted into a small hole made in the stem of a amaranth plant 5 to $7 \mathrm{~cm}$ above soil level using a dissecting needle. Each hole was covered with parafilm after inoculation to prevent desiccation and contamination. Five replicate plants were inoculated with one each of the 30 isolates of $F$. oxysporum. Control inoculations were performed with toothpick tips prepared as described above but incubated on sterile PDA.

The temperature in the greenhouse varied between 15 and $28^{\circ} \mathrm{C}$. Plants were watered daily and fertilized weekly with a hydroponic nutrient solution $(10 \mathrm{~g} /$ liter of water; $50 \mathrm{ml}$ per pot) containing $\mathrm{N}(5.6 \%)$, $\mathrm{P}(4.6 \%), \mathrm{K}(2.74 \%), \mathrm{Mg}(3 \%), \mathrm{S}(11.2 \%)$, $\mathrm{Fe}(0.069 \%), \mathrm{Mn}(0.03 \%), \mathrm{Zn}(0.027 \%), \mathrm{B}$ $(0.044 \%), \mathrm{Cu}(0.014 \%)$, and Mo $(0.009 \%)$. Plants were observed every other day for disease development. After incubation for 4 weeks in the greenhouse, the plants were harvested and the stems of all five replications of each isolate were cut longitudinally at the inoculation wound with a sterile knife. Length of the necrotic lesion extending either side of the inoculation wound was measured. A randomized complete block design was used and the experiment was conducted twice.

Analysis of variance (ANOVA) was conducted with ANOVA of NCSS 2000 (BMDP Statistical Software, Inc., Los Angeles). The experiment was treated as a block, the isolate was treated as an experimental factor, and the interaction of experiment-isolate was used as an error term to determine the significance of variance in lesion length among experiments and isolates. This error term was also used in multiple comparisons among isolates by DUNCAN comparison method after determination of insignificance between two experiments. To verify that necrosis was caused by the particular isolate of $F$. oxysporum that had been inoculated, one piece of stem tissue from each of the 150 inoculated plants was taken from each side of the toothpick insertion point, plated on $50 \%$ PDA, incubated for 4 to 5 days, and examined for the presence of $F$. oxysporum.

Vegetative compatibility tests. Mutants were generated for each isolate as described by Correll et al. (7) and Correll (5), using minimal medium or PDA containing $1.5 \%$ potassium chlorate. For isolates that failed to form mutants on either of these two media, chlorate concentrations were increased to $3 \%$ or higher, or isolates were transferred to a rose bengal-amended medium for selecting nitrate-metabolism mutants (10). Mutant sectors appearing on the chlorate media were transferred to minimal medium (MM) containing nitrate as the sole nitrogen source. Colony sectors with thin, expansive growth and no aerial mycelium were assumed to be nitrate nonutilizing mutants (nits). Subsequent transfer to minimal medium with nitrate, nitrite, or hypoxanthine was used to identify the physiological phenotypes. Sparse growth on nitrate, hypoxanthine, or nitrite-contain- ing medium determined a nit 1 , nit $\mathrm{M}$, or nit 3 phenotype, respectively $(6,7)$. At least one nit $\mathrm{M}$ and one nit 1 or nit 3 were obtained for each isolate.

Pairings between isolates were made on $\mathrm{MM}$ in $90-\mathrm{mm}$ petri plates. All isolates were paired in all possible combinations and with a positive control. A mycelial plug of a nit $\mathrm{M}$ was placed in the center of the plate and surrounded at a distance of 10 $\mathrm{mm}$ by four nit $1 \mathrm{~s}$ or nit $3 \mathrm{~s}$ in a "daisy" configuration as described by Puhala (24). The plates were incubated in the dark at $28^{\circ} \mathrm{C}$ for up to 14 days. Wild-type growth in the contact zone between any two mutants indicated that the two isolates belonged to the same VCG. Sparse growth in the contact zone indicated that the isolates belonged to different VCGs. All pairings were performed twice.

Isozyme analysis. All isolates were grown on PDA in petri plates for 5 days at $25^{\circ} \mathrm{C}$. Each isolate was prepared for electrophoresis by inoculating $100 \mathrm{ml}$ of PDB in a 500-ml flask with a single mycelial plug taken from the edge of a growing colony. Inoculated flasks were shaken continuously at $90 \mathrm{rpm}$ for 6 days at room temperature $\left(24 \pm 1^{\circ} \mathrm{C}\right)$. Mycelium was harvested from the broth by filtration through two layers of cheesecloth, washed three times with sterile distilled water, dried on filter paper, and ground in liquid nitrogen using a mortar and pestle. A 1.5$\mathrm{ml}$ Eppendorf tube was filled halfway up the conical portion with ground mycelium. One milliliter of extraction buffer $(1.21 \mathrm{~g}$ of Tris, $0.292 \mathrm{~g}$ of EDTA, $38 \mathrm{mg}$ of NADP per liter of distilled water, $0.5 \%$ polyvinylpyrrolidone 360 ) was added to the tube, which was shaken vigorously for $10 \mathrm{~min}$, then centrifuged for $5 \mathrm{~min}$ in a tabletop centrifuge at 9,000 rpm. The supernatant was collected and frozen at $-75^{\circ} \mathrm{C}$ until assayed.

Starch gel electrophoresis and staining procedures were conducted according to the procedures of Bonde et al. (2) and Michales et al. (20,21). Fifteen enzymes were tested for activity in four buffer sys-

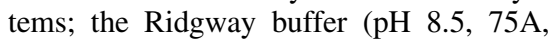
4h) was used throughout this study because it provided the best results. Each of the isolates of $F$. oxysporum were screened for isozyme activity at least twice. Thirty isolates of $F$. oxysporum from all six substrates were characterized using the seven selected enzymes: esterase (EST, EC no. 3.1.1.1); isocitrate dehydrogenase (IDH, EC no. 1.1.1.42); glucose-6-phosphate dehydrogenase (G6PDH, EC no. 1.1.1.49); acid phosphatase (ACP, EC no. 3.1.3.2); and peptidase (PEP, EC no. 3.4.11) using glycyl-leucine (GL), leucyl-tyrosine (LT), and leucyl-glycyl-glycine (LGG) as substrates. Isozyme bands were recorded as 0 if absent or 1 if present in the data matrix for each enzyme. Each isolate of $F$. oxysporum was assigned to a phenotype class based on the banding pattern. To determine 
relatedness of the fungal isolates, cluster analysis was performed for similarity coefficients by using the unweighted pair-group method with arithmetic averages (UPGMA) in the statistical program NCSS 2000 (BMDP Statistical Software, Inc.).

\section{RESULTS}

More than 200 isolates of $F$. oxysporum were recovered from the six different substrates. Thirty isolates were chosen based on the frequency that they were recovered from each of the six substrates for characterization of their genetic relatedness.

Pathogenicity tests. All 30 isolates were pathogenic on A. hybridus plants, producing significantly longer $(P<0.05)$ necrotic lesions on stems (mean $=18 \mathrm{~mm}$, range 13 to $28 \mathrm{~mm}$; Table 1 ) than on noninoculated control treatments (mean $=8$ $\mathrm{mm})$. ANOVA demonstrated that there was no significant difference in lesion length $(P$ $=0.8459$ ) between the two experiments, while there was a significant difference among isolates $(P<0.001)$. No relationship was observed between VCGs and pathogenicity. F. oxysporum was reisolated from each of the inoculated plants but not from any of the noninoculated plants.

Vegetative compatibility tests. A total of 765 chlorate-resistance mutants were obtained from the 30 isolates. Between 3 and 25 nits were obtained from each isolate of $F$. oxysporum. Isolates differed in the number of mutants recovered and the phenotypic ratio of nits recovered, although sectoring frequency per isolate was not recorded. The nit 1 phenotype was recovered most frequently $(49.5 \%$ of all mutants), followed by nit $\mathrm{M}(26.7 \%)$ and nit 3 (6.3\%). The most evident pairing (regeneration of wide type growth) was the combination of nit 1 and nit $\mathrm{M}$. For each isolate of $F$. oxysporum, the nits and the tester strains formed hetrokaryons evident by robust growth at the interface of the two colonies. Self-incompatibility was not observed between complementary nits and the original isolates of $F$. oxysporum.

The 30 isolates of $F$. oxysporum fell into nine VCGs. Of these, the largest group (VCG 1) included 20 of the isolates. Seven

Table 1. Isolate number, substrate from which isolates were recovered, lesion length resulting from inoculation of Amaranthus hybridus, and vegetative compatibility group (VCG) of 30 isolates of Fusarium oxysporum ${ }^{v}$

\begin{tabular}{|c|c|c|c|c|}
\hline Isolate & Designation $^{w}$ & Substrate for isolation ${ }^{x}$ & Lesion length $(\mathrm{mm})^{\mathrm{y}}$ & $\mathrm{VCG}^{\mathrm{z}}$ \\
\hline 28 & Db6 & Dry bean rhizosphere & $28 \mathrm{a}$ & 9 \\
\hline 26 & M3 & Maize rhizosphere & $26 \mathrm{ab}$ & 1 \\
\hline 6 & 106 & Amaranth soil & $22 \mathrm{bc}$ & 1 \\
\hline 12 & 78 & Amaranth tap root & $22 \mathrm{bc}$ & 1 \\
\hline 24 & 169.1 & Weevil & $22 \mathrm{bc}$ & 1 \\
\hline 4 & 104 & Amaranth soil & $22 \mathrm{bc}$ & 1 \\
\hline 9 & 48 & Amaranth tap root & $22 \mathrm{bc}$ & 3 \\
\hline 13 & 79 & Amaranth tap root & $21 \mathrm{~cd}$ & 1 \\
\hline 2 & 102 & Amaranth soil & 20 cde & 1 \\
\hline 1 & 101 & Amaranth soil & $18 \mathrm{cdef}$ & 1 \\
\hline 20 & 139.1 & Weevil & $18 \mathrm{cdef}$ & 1 \\
\hline 5 & 105 & Amaranth soil & $18 \mathrm{cdef}$ & 1 \\
\hline 25 & M1 & Maize rhizosphere & $18 \mathrm{cdef}$ & 1 \\
\hline 18 & 23.2 .3 & Weevil & 17 defg & 5 \\
\hline 3 & 103 & Amaranth soil & 17 defg & 1 \\
\hline 7 & 109 & Amaranth soil & 17 defg & 2 \\
\hline 27 & M5 & Maize rhizosphere & 17 defg & 8 \\
\hline 21 & 138.1 & Weevil & 17 defg & 6 \\
\hline 15 & Srr10 & Amaranth side root & 17 defg & 1 \\
\hline 23 & 148.1 & Weevil & $16 \mathrm{efg}$ & 1 \\
\hline 17 & Srr14 & Amaranth side root & $16 \mathrm{efg}$ & 1 \\
\hline 30 & $\mathrm{Db} 2$ & Dry bean rhizosphere & $16 \mathrm{efg}$ & 1 \\
\hline 10 & 63 & Amaranth tap root & $16 \mathrm{efg}$ & 3 \\
\hline 11 & 58 & Amaranth tap root & $15 \mathrm{fg}$ & 3 \\
\hline 22 & 145.1 & Weevil & $15 \mathrm{fg}$ & 7 \\
\hline 14 & Srr1 & Amaranth side root & $15 \mathrm{fg}$ & 1 \\
\hline 29 & Db1 & Dry bean rhizosphere & $14 \mathrm{fg}$ & 1 \\
\hline 19 & 69.2 & Weevil & $14 \mathrm{fg}$ & 1 \\
\hline 8 & 35 & Amaranth tap root & $13 \mathrm{~g}$ & 1 \\
\hline 16 & Srr12 & Amaranth side root & $13 \mathrm{~g}$ & 4 \\
\hline
\end{tabular}

${ }^{v}$ Means followed by the same letter are not significantly different $(P \leq 0.05)$ according to Duncan's multiple range test.

${ }^{\mathrm{w}}$ Isolates of $F$. oxysporum recovered from symptomatic roots were made on potato-dextrose agar amended with streptomycin sulfate after surface sterilization. Isolates recovered from soil debris were made on Van Wyk's selective medium (28). Isolates recovered from weevils were made by plating dead weevils onto $2 \%$ malt-extract agar.

x Tap root and side root samples were all from A. hybridus plants, and from roots showing symptoms of root rot. Weevil = pigweed weevil (Hypolixus haerens).

${ }^{y}$ Mean length of necrotic lesion produced on amaranth stems following inoculation with $F$. oxysporum-infested toothpicks (average of 10 plants from five replications and two experiments per isolate from two trials).

${ }^{\mathrm{z}}$ Isolates from different VCGs were not compatible. of the VCGs consisted of a single isolate, and one VCG (VCG3) consisted of three isolates (Table 1). Isolates within a VCG were not compatible with isolates from another VCG. Self-incompatibility was not observed between complementary nits recovered from single isolates of $F$. $o x$ ysporum.

Isozyme analysis. Of the seven enzymes evaluated, EST, ACP, and G6PDH produced the most intensive bands. Bands of IDH and PEP3 were weaker, and their intensity decreased after extraction samples had been stored for more than 2 weeks. A total of 126 electrophoretic phenotypes was detected among the 30 isolates of $F$. oxysporum examined. The number of electrophoretic phenotypes varied among substrates from which the isolates were recovered. Three major groups of $F$. oxysporum, designated I, II, and III, were delineated by the cluster analysis (Fig. 1). No relationship was found between isozyme groups and the substrates from which the isolates were recovered; for example, group II included three isolates recovered from the maize rhizosphere, one isolate from dry bean rhizosphere, and one isolate from a pigweed weevil.

\section{DISCUSSION}

Based on the biological and genetic characteristics evaluated in this study, the population of $F$. oxysporum colonizing amaranth roots appears to be relatively homogeneous and genetically indistinct from isolates obtained from associated pigweed weevils and from an adjacent field of maize and dry bean. These results are similar to those of Bosland et al. (3), who classified isolates of $F$. oxysporum from crucifers into subspecific taxa according to their pathogenicity, isozyme polymorphism, and vegetative compatibility. They found little variation in isozyme patterns among isolates of $F$. oxysporum for 15 of 18 enzymes examined. This uniformity shows that $F$. oxysporum is consistent with respect to enzyme profile; therefore, not much polymorphism should be expected. However, only seven enzymes were evaluated in this study, and greater variation in isozyme patterns may have been found if a greater number of enzymes were evaluated.

Our results are relatively consistent with a number of studies on Fusarium VCGs that demonstrate a lack of genetic diversity. For example, a collection of 44 isolates of $F$. oxysporum Schlechtend.:Fr. f. sp. albedinis (Killian \& Maire) Gordon, causing Bayoud disease of date palm, all belonged to a single VCG, and no polymorphisms were observed in restriction fragment length polymorphism studies from mitochondrial DNA and random amplified polymorphic DNA analysis (26). All 47 isolates of $F$. oxysporum f. sp. apii collected from celery showing wilt symptoms belonged to a single VCG (7). Iso- 
lates of $F$. oxysporum f. sp. melonis collected from a single field in California also were represented by a single VCG (16). Nine VCGs were recovered in the current study, but two-thirds of the isolates assayed belonged to a single VCG and included isolates recovered from all six substrates. The second largest VCG was only represented by three isolates, and the remaining seven VCGs by only one isolate each. Isolates of $F$. oxysporum from the single-member VCGs clustered into the same group as isolates assigned to VCG1 by isozyme analysis (Fig. 1). Elias and Schneider (11) similarly recovered a number of single-member VCGs of $F$. $o x$ ysporum f. sp. lycopersici, whose electrophoretic phenotypes clustered with the multiple-member VCGs, providing evidence for their recent development from the multiple-member VCGs. The isolates of single-member VCGs grouped into the same clade with members in VCG1 by isozyme analysis (Fig. 1), suggesting that they may have been members of major VCGs that underwent a simple mutation at one or more of the vegetative compatibility loci, such that they can no longer form heterokaryons with the other members.

There was no association between VCGs and the different sources from which the isolates of $F$. oxysporum were recovered. For example, VCG3 included three isolates recovered from diseased tap roots, but three other isolates from the same source were assigned to VCG1. Isolates of $F$. oxysporum recovered from phytophagous weevils, and shown to be pathogenic in artificial inoculations of potted amaranth plants, were distributed among four VCGs, of which the majority were from VCG1 and three were specific to weevils (Table 1). This suggests that pigweed weevils carry spores of $F$. oxysporum which they inadvertently acquire from a wide range of niches and localities. The recovery of isolates in VCG1 from different sources also suggests that this genetically homogeneous population is widespread among various ecological niches.

Commercial cultivation of amaranth is at a very early stage of development in South Africa, suggesting that a more diverse pathogen population within $F$. oxysporum may develop in future. Additional work is needed on $F$. oxysporum populations pathogenic to amaranth, including evaluation of isolates from more diverse locations. The host range of isolates of $F$. oxysporum pathogenic to A. hybridus should also be examined to determine whether they are specific to this host. These results could provide valuable information on the origin and spread of this soil inhabitant and might suggest novel methods, such as crop rotation, for controlling

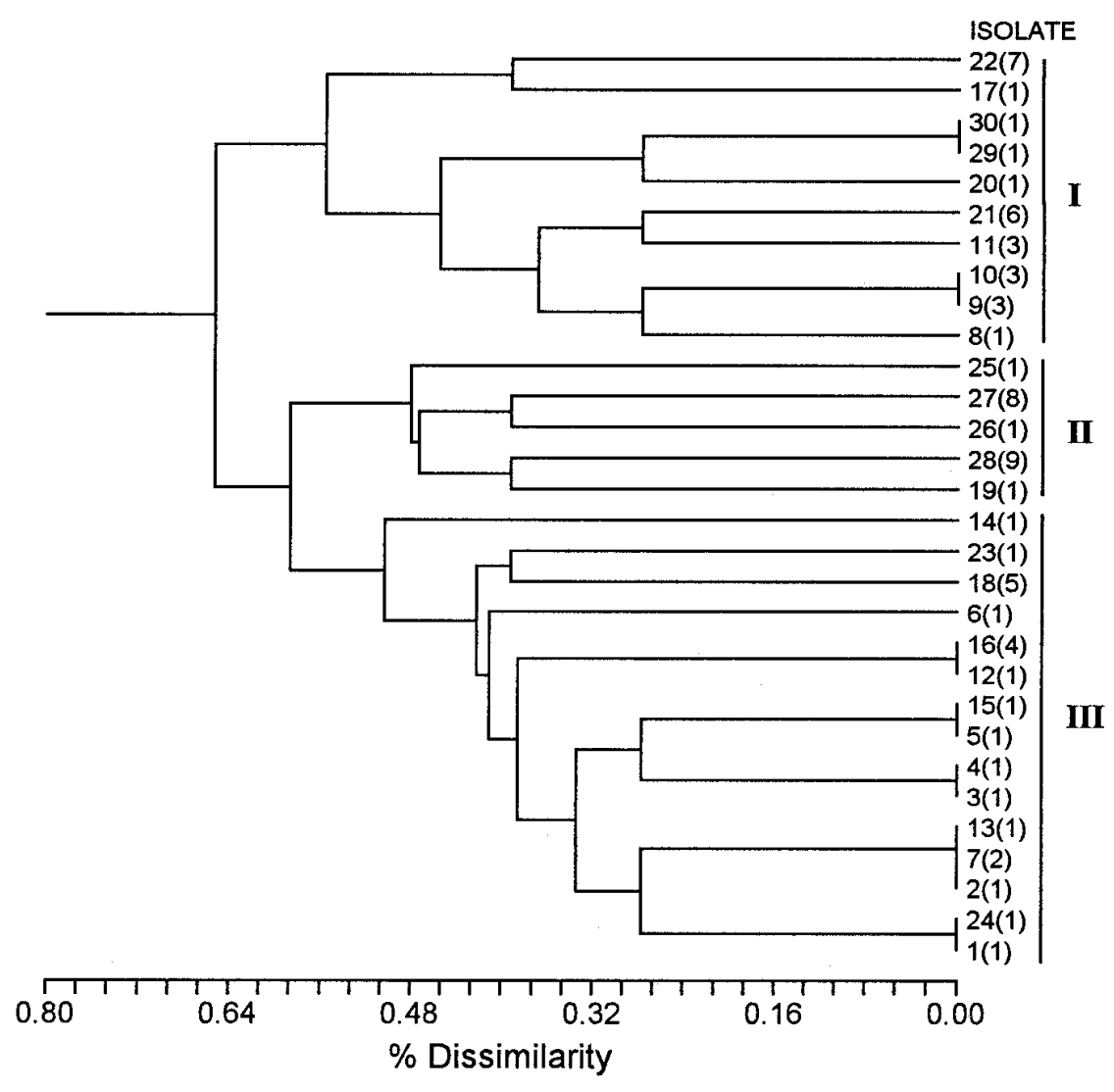

Fig. 1. Dendrogram based on isozyme analysis of 30 isolates of Fusarium oxsysporum, recovered from amaranth plants and other substrates (maize and dry bean rhizosphere, weevils), using the unweighted pair-group method with arithmetic averages (NCSS 2000; BMDP Statistical Software Inc., Los Angeles). root rot of A. hybridus. It also follows that, when selecting for resistance in $A$. hybridus to $F$. oxysporum, strict attention should be paid to the level of variation that exists within the local population of the pathogen. An integrated pest management program involving cultural practices, selection for disease resistance, and biological or chemical control of pigweed weevils should therefore go a long way to reduce losses associated with $F$. oxysporum in amaranth plantings.

\section{ACKNOWLEDGMENTS}

We thank those who reviewed this manuscript for their thoughtful and helpful suggestions, and Y. Lou for his help with statistical analysis.

\section{LITERATURE CITED}

1. Blodgett, J. T., Swart, W. J., and Louw, S. vdM. 1998. First report of Fusarium sambucinum, $F$. oxsysporum, and $F$. subglutinans associated with stem decay of Amaranthus hybridus in South Africa. Plant Dis. 82:1062.

2. Bonde, M. R., Micales, J. A., and Peterson G. L. 1993. The use of isozyme analysis for identification of plant-pathogenic fungi. Plant Dis. 77:961-968.

3. Bosland, P. W., and Williams, P. H. 1987. An evaluation of Fusarium oxysporum from crucifers based on pathogenicity, isozyme polymorphism, vegetative compatibility and geographic origin. Can. J. Bot. 65:2067-2073.

4. Chen, W. Q., and Swart, W. J. 2000. Fusarium oxysporum and $F$. sambucinum associated with root rot of Amaranthus hybridus in South Africa. Plant Dis. 84:101.

5. Correll, J. C. 1991. The relationship between formae speciales, races, and vegetative compatibility groups in Fusarium oxysporum. Phytopathology 81:1061-1064.

6. Correll, J. C. 1992. Genetic, biochemical and molecular techniques for the identification and detection of soil borne plant-pathogenic fungi. Pages 1-10 in: Methods for Research on Soilborne Phytopathogenic Fungi. L. L. Singleton, J. D. Mihail, and C. M. Rush, eds. American Phytopathological Society Press, St. Paul, MN.

7. Correll, J. C., Klittich, C. J. R., and Leslie, J. F. 1987. Nitrate nonutilizing mutants of Fusarium oxysporum and their use in vegetative compatibility tests. Phytopathology 77:16401646.

8. Correll, J. C., Puhalla, J. E., and Schneider, R. W. 1986. Identification of Fusarium oxysporum f. sp. apii on the basis of colony size, virulence, and vegetative compatibility. Phytopathology 76:396-400.

9. Elena, K., and Tjamos E. C. 1995. Vegetative compatibility groups of Fusarium oxsysporum f. sp. dianthi from plants and the rhizosphere of carnation in Greece. Plant Pathol. 44:148152.

10. Elias, K. S., and Cotty, P. J. 1995. A rose bengal amended medium for selecting nitrate-metabolism mutants from fungi. Can. J. Bot 73:680-682.

11. Elias, K. S., and Schneider, R. W. 1992. Genetic diversity within and among races and vegetative compatibility groups of Fusarium oxysporum f. sp. lycopersici as determined by isozyme analysis. Phytopathology 82:14211427.

12. Elmer, W. H., and Stephens, C. T. 1989. Classification of Fusarium oxysporum f. sp. asparagi into vegetatively compatible groups. Phytopathology 79:88-93.

13. Gerlach, W., and Nirenberg, H. 1982. The genus Fusarium - a Pictorial Atlas. Mitt. Biol. Bundesanst. Land-Fortwirtsch. Berl.-Dahl. 
209:1-406.

14. Gordon, T. R., and Okamoto, D. 1991. Vegetative compatibility groupings in a local population of Fusarium oxysporum. Can. J. Bot. 69:168-172.

15. Honiball, S. J., Louw, S. vdM., Swart, W. J., and Chen, W. Q. 1999. Fungi associated with phytophagous weevils on Amaranthus hybridus in the central Free State, South Africa. Page 58 in: Proc. 12th S. Afr. Entomol. Congr. Potchefstoom, South Africa.

16. Jacobson, D. J., and Gordon, T. R. 1990. Further investigation of vegetative compatibility within Fusarium oxysporum f. sp. melonis. Can. J. Bot. 68:1245-1248.

17. Katan, T., and Katan, J. 1988. Vegetative compatibility grouping of Fusarium oxysporum f. sp. vasinfectum from tissue and the rhizosphere of cotton plants. Phytopathology 78:852-855

18. Kistler, H. C., Alabouvette, C., Baayen, R. P., Bentley, S., Brayford, D., Coddington, A., Correll, J., Daboussi, M.-J., Elias, K., Fernandez, D., Gordon, T. R., Katan, T., Kim, H. G., Leslie, J. F., Martyn, R. D., Migheli, Q., Moore, N. Y., O’Donnell, K., Ploetz, R.
C., Rutherford, M. A., Summerell, B., Waalwijk, C., and Woo, S. 1998. Systematic numbering of vegetative compatibility groups in the plant pathogenic fungus Fusarium oxsysporum. Phytopathology 88:30-32.

19. Louw, S. vdM., van Eeden, C. F., and Weeks, W. J. 1995. Curculionidae (Coleoptera) associated with wild and cultivated Amaranthus spp. (Amaranthaceae) in South Africa. Afr. Crop Sci. J. 3(1): 93-98.

20. Micales, J., Bonde, M., and Peterson, G. 1986. The use of isozyme analysis in fungal taxonomy and genetics. Mycotaxon 27:405449.

21. Micales, J., Bonde, M., and Peterson, G. 1992. Isozyme analysis in fungal taxonomy and molecular genetics. Pages 57-79 in: Handbook of Applied Mycology, Fungal Biotechnology, Vol. 4. D. Arora, R. Elander., and K. Mukerji, eds. Marcel-Dekker, Inc., New York.

22. Nelson, P. E., Toussoun, T. A., and Marasas, W. F. O. 1983. Fusarium species: An Illustrated Manual for Identification. The Pennsylvania State University Press, University Park.

23. Paavanen-Huhtala, S., Hyvonen, J., Bulat, S. A., and Yli-Mattila. 1999. RAPD-PCR, isozyme, rDNA RFLP and rDNA sequence analysis in identification of Finnish Fusarium oxysporum isolates. Mycol. Res. 103:625-634.

24. Puhalla, J. E. 1985. Classification of strains of Fusarium oxysporum on the basis of vegetative compatibility. Can. J. Bot. 63:179-183.

25. Skovgaard, K., and Rosendahl, S. 1998. Comparison of intra- and extracellular isozyme banding patterns of Fusarium oxysporum. Mycol. Res. 102:1077-1084.

26. Tantaoui, A., Ouinten, M., Geiger, J. P., and Fernandez, D. 1996. Characterization of a single clonal lineage of Fusarium oxysporum $\mathrm{f}$. sp. albedinis causing bayoud disease of date palm in Morocco. Phytopathology 86:787-792.

27. Vakalounakis, D. J., and Fragkiadakis, G. A 1999. Genetic diversity of Fusarium oxysporum isolates from cucumber: Differentiation by pathogenicity, vegetative compatibility, and RAPD fingerprinting. Phytopathology 89:161-168.

28. Van Wyk, P. S., Scholtz, D. J., and Los, O. 1986. A selective medium for the isolation of Fusarium spp. from soil debris. Phytophylactica 18:67-69. 